\title{
Optimisation of Diesel Polluted Soil Using Response Surface Methodology
}

\author{
Olawale O. ${ }^{2,}$, , Oyawale F. A. ${ }^{1}$, Adepoju T. F. ${ }^{2}$, Aikulolu S. ${ }^{2}$, Akinmoladun A. I. ${ }^{3}$ \\ ${ }^{1}$ Mechanical Engineering Department, Covenant University, Otta, Nigeria \\ ${ }^{2}$ Chemical Engineering Department, Landmark University, Omu Aran, Kwara State, Nigeria \\ ${ }^{3}$ Department of Physics and Technology, Bronx Community College of the City University of New York, New York, USA
}

\section{Email address:}

Lamstock2@yahoo.com (Olawale O.), Olawale.olamide@1mu.edu.ng (Olawale O.)

\section{To cite this article:}

Olawale O., Oyawale F. A., Adepoju T. F., Aikulolu S., Akinmoladun A. I. Optimisation of Diesel Polluted Soil Using Response Surface Methodology. International Journal of Environmental Protection and Policy. Vol. 3, No. 6, 2015, pp. 194-202.

doi: 10.11648/j.ijepp.20150306.13

\begin{abstract}
This research is based on the investigation of the bioremediation of diesel polluted soil using biostimulation strategy. The study was carried out on a diesel contaminated soil and concentrations: Tween $80(5-15 \mathrm{ml})$, Poultry droppings (20-60g), Hydrogen Peroxide (0.5-1.5ml) were added and incubated for 28 days of remediation period. Response Surface Methodology with Box-Behnken Design (BBD) was used with three factors and three levels of Tween 80, Poultry droppings and Hydrogen Peroxide as independent variables while diesel oil (Total Petroleum Hydrocarbon) removal was the dependent variable (response). The result showed disparities in the diesel oil biodegradation pattern with respect to Tween 80, Poultry droppings and Hydrogen Peroxide. The statistical analysis, via ANOVA showed coefficient of determination $\mathrm{R}^{2}$ to be $99.89 \%$ and $\mathrm{P}<0.05$. The predicted optimum parameter of Tween $80: 10.10 \mathrm{ml}$, Poultry droppings: $41.46 \mathrm{~g}$ and Hydrogen Peroxide: $1.10 \mathrm{ml}$ were gotten while $56.565 \%$ was gotten as the optimal diesel oil removal. At this optimum condition, the observed diesel oil removal was found to be $56.568 \%$. It can be concluded that bioremediation of diesel-contaminated soil resulted in petroleum hydrocarbon degradation.
\end{abstract}

Keywords: Bioremediation, Diesel, Tween 80, Soil

\section{Introduction}

Diesel is a fuel obtained from petroleum distillation and it is used in diesel engines. It is a lightweight mixture of liquid hydrocarbons and has a relatively low ignition temperature $\left(540^{\circ} \mathrm{C}\right)$ and is ignited by the heat of compression. It is produced from the fractional distillation of crude oil between $200^{\circ} \mathrm{C}\left(392^{\circ} \mathrm{F}\right)$ and $350^{\circ} \mathrm{C}\left(662^{\circ} \mathrm{F}\right)$ at atmospheric pressure. When the soil becomes contaminated, the ecosystem is altered and agricultural activities are affected seriously due to this pollution. [5]; stated that used or improperly disposed diesel fuel contains potentially toxic substances, such as: benzene (carcinogens), lead, arsenic, zinc and cadmium, which can seep into the ground and contaminate ground water. Furthermore, it is common to observe diesel spills from the cleaning of oil tankers and also via the disposal of used oil from diesel cars by the road side mechanics. Physicochemical technologies have been previously used for the remediation of polluted soils [8].
According to [3]; bioremediation technology through the mechanism of biodegradation has been recognized to be a valuable alternative for the detoxification and disposal of toxic substances. This is because it is environment-friendly, financially viable, and technologically simple and it also conserves soil texture and characteristics.

Furthermore, bioremediation is an ecologically acceptable technology that is used for the removal of a pollutant from the biosphere through the use of microorganisms [13]. It relies on biological processes to minimize unwanted environment impact of the pollutants. Nevertheless, this Research is focused on biostimulation method. According to [11]; biostimulation is the addition of nutrients to a polluted site in order to encourage the growth of naturally occurring chemical degrading microorganisms. This research is based on optimising diesel polluted soil. 


\section{Materials and Method}

\subsection{Method}

Diesel-contaminated soil was excavated from the Generator House at Landmark University Cafeteria, OmuAran, Kwara State, Nigeria between $0-30 \mathrm{~cm}$ from the soil surface. The soil was sieved with $5 \mathrm{~mm}$ sieve. Organic wastes was used in this study instead of NPK fertilizer, to facilitate aeration through small pores to increase the water-holding capacity of the soil; thus enhancing bioremediation. The organic wastes used in this study was collected from Landmark University Research Poultry Farm. Physicochemical properties of organic wastes and soil employed were determined using standard methods.

\subsection{Physicochemical Property Determination for Soil}

Physicochemical properties determined for soil included $\mathrm{pH}$, water holding capacity, textural class as well as Nitrogen, Potassium, Carbon and Phosphorus content.

\subsection{Soil pH Determination}

$10 \mathrm{~g}$ of sieved $(\leq 5 \mathrm{~mm})$ and air-dried soil was weighed poured into a $50 \mathrm{ml}$ beaker and $25 \mathrm{ml}$ of distilled water added. The content was stirred manually for 30 minutes with a glass rod and left to stand for 1 hour. The electrode of the $\mathrm{pH}$ meter (Kent EIL 7055) was then inserted and the $\mathrm{pH}$ determined.

\subsection{Determination of Water Holding Capacity (WHC)}

Six (6) inches of soil was placed in percolation tube and compacted by gentle bouncing. Water was added until the water level reached 2 inches above soil level. The tube was covered and left to stand for 2 days. After this period, the top half-inch of soil was discarded and wet soil was weighed into a pre-weighed evaporating dish. The sample was placed in oven at $110^{\circ} \mathrm{C}$ for $24 \mathrm{~h}$. It was then removed and weighed to obtain bone dry weight of the sample. Percentage water holding capacity was calculated as [12]:

$$
\% \text { waterholdingwater }=\frac{\text { wetweight-bonedryweight }}{\text { bonedryweight }}
$$

\subsection{C, N, P and K Content}

Soil textural class, as well as soil carbon, nitrogen, phosphorus and phosphorus contents were analyzed at the Civil Laboratory of Landmark University, Omu-Aran, Kwara state. Soil textural class was determined using the hydrometer method [7]. The organic carbon, phosphorus and nitrogen contents were determined using an element detector.

\subsection{Bioremediation Setup}

$200 \mathrm{~g}$ of diesel polluted soil was placed in plastic bottles, labeled 1 to 17 . Organic wastes (poultry droppings), $\mathrm{H}_{2} \mathrm{O}_{2}$ and Tween 80 were added to each of the diesel polluted soil in appropriate conditions. The soil was then mixed daily to provide sufficient aeration and moistened by the addition of water every other day to adjust the water holding capacity at
$60 \%$ throughput throughout the experimental period. The plastic bottles were then incubated at room temperature. The controls contained only diesel polluted soil.

\subsection{Experimental Procedure}

Polluted soil samples $(200 \mathrm{~g})$ were placed in plastic bottles (microcosm). The diesel-contaminated soil in each plastic bottle was amended with different amounts of poultry dung $(20-60 \mathrm{~g})$, Tween $80(5-15 \mathrm{mg} / \mathrm{l})$ and hydrogen peroxide $(0.5-1.5 \mathrm{~g} / \mathrm{l})$, respectively. Soil used as control was not amended with any biostimulating agents. In total, 17 microcosms were settled and incubated for 28 days. All microcosms were mixed manually once per week to enhance oxygenation, and kept moist during the 28 day experimental period. Samples were withdrawn after the incubation period for percentage diesel removal analysis.

\subsection{Experimental Design and Data Analysis}

Table 1. Experimental range and the levels of the variables.

\begin{tabular}{llll}
\hline Factors & $\begin{array}{l}\text { High level } \\
(+\mathbf{1})\end{array}$ & $\begin{array}{l}\text { Medium } \\
\text { level (0) }\end{array}$ & $\begin{array}{l}\text { Low level } \\
(\mathbf{- 1 )}\end{array}$ \\
\hline Tween 80 (A) ml & 5 & 10 & 15 \\
Poultry Droppings (B) & 20 & 40 & 60 \\
Hydrogen Peroxide (C) $\mathrm{ml}$ & 0.5 & 1.0 & 1.5 \\
\hline
\end{tabular}

Table 2. Full-factorial Box-Behnken design for the three independent variables.

\begin{tabular}{|c|c|c|c|c|c|c|}
\hline \multirow[t]{2}{*}{ Run } & \multicolumn{2}{|c|}{$\begin{array}{l}\text { Factor } 1 \\
\text { A: Tween } 80(\mathrm{ml})\end{array}$} & \multicolumn{2}{|c|}{$\begin{array}{l}\text { Factor } 2 \\
\text { B: Poultry } \\
\text { Droppings (g) }\end{array}$} & \multicolumn{2}{|c|}{$\begin{array}{l}\text { Factor C } \\
\text { C: Hydrogen } \\
\text { Peroxide (ml) }\end{array}$} \\
\hline & Coded & Uncoded & Coded & Uncoded & Coded & Uncoded \\
\hline 1 & 0 & 10.00 & +1 & 60.00 & -1 & 0.50 \\
\hline 2 & 0 & 10.00 & 0 & 40.00 & 0 & 1.00 \\
\hline 3 & +1 & 15.00 & 0 & 40.00 & -1 & 0.50 \\
\hline 4 & +1 & 15.00 & 0 & 40.00 & +1 & 1.50 \\
\hline 5 & 0 & 10.00 & -1 & 20.00 & +1 & 1.50 \\
\hline 6 & 0 & 10.00 & 0 & 40.00 & 0 & 1.00 \\
\hline 7 & +1 & 15.00 & -1 & 20.00 & 0 & 1.00 \\
\hline 8 & 0 & 10.00 & 0 & 40.00 & 0 & 1.00 \\
\hline 9 & -1 & 5.00 & -1 & 20.00 & 0 & 1.00 \\
\hline 10 & -1 & 5.00 & 0 & 40.00 & -1 & 0.50 \\
\hline 11 & 0 & 10.00 & +1 & 60.00 & +1 & 1.50 \\
\hline 12 & -1 & 5.00 & 0 & 40.00 & +1 & 1.50 \\
\hline 13 & +1 & 15.00 & +1 & 60.00 & 0 & 1.00 \\
\hline 14 & -1 & 5.00 & +1 & 60.00 & 0 & 1.00 \\
\hline 15 & 0 & 10.00 & 0 & 40.00 & 0 & 1.00 \\
\hline 16 & 0 & 10.00 & 0 & 40.00 & 0 & 1.00 \\
\hline 17 & 0 & 10.00 & -1 & 20.00 & -1 & 0.50 \\
\hline $\begin{array}{l}18 \\
\text { control }\end{array}$ & & - & & - & & - \\
\hline
\end{tabular}

The Box-Behnken factorial experimental design employed had three independent variables: Tween 80 (surfactant), Poultry droppings (nutrient) and hydrogen peroxide. Each of the independent variables was studied at three levels $(1,0$, +1 ), with 17 experimental runs and one control. The levels were selected based on preliminary study results and literature. The variables optimized were Tween $80(5-15$ 
$\mathrm{mg} / \mathrm{l})$, Poultry droppings $(20-60 \mathrm{~g})$ and hydrogen peroxide $(0.5-1.5 \mathrm{~g} / \mathrm{l})$ at three levels, respectively were shown in Table 1. Efficiency of diesel removal was assessed after 28 days. Table 2 shows the coded and actual values of factors and levels used in the experimental design. Diesel contaminated soil without biostimulation was also analyzed as a control. The statistical software Design Expert 6.0.8, (Stat-Ease Inc., Minneapolis, USA) was used to evaluate the analysis of variance $(\mathrm{P}<0.05)$ to determine the significance of each term in the fitted equations and to estimate the goodness of fit in each case.

\subsection{Total Petroleum Hydrocarbon Analysis}

The TPH analysis was carried to determine the percentage diesel removed using the gravimetric method. $10 \mathrm{~g}$ of each treatment was collected and dried at room temperature for 72 hours. $5 \mathrm{~g}$ of the soil was placed in 200 milliliters beaker and $150 \mathrm{ml}$ of toluene was added. The mixture was stirred continuously for $30 \mathrm{~min}$, left to stand in a fume cupboard for 2 hours and then filtered using Whatman No 42 filter paper. The residue, (soil), was allowed to dry in an oven at $50^{\circ} \mathrm{C}$. The TPH was calculated according to [1]; [2]:

$$
\% \text { Diesel Removal }\left(\frac{\mathrm{g}}{\mathrm{kg}}\right)=
$$

(initial weight of soil-weight of soil after soil extraction)ing

$$
\text { initial weight of soil in } \mathrm{kg}
$$

\section{Results and Discussions}

\subsection{Soil Parameters}

Table 3 showed the values for the soil parameters that were tested.

Table 3. Soil Parameters for the Diesel-polluted soil.

\begin{tabular}{ll}
\hline Parameters & Values \\
\hline Soil Ph & 7.29 \\
Water holding capacity & $16( \pm 2) \%$ \\
Nitrogen content & $0.34 \mathrm{mg} / 1$ \\
Potassium content & $6.0 \mathrm{mg} / 1$ \\
Calcium content & $26 \mathrm{mg} / 1$ \\
Phosphorus content & $0.15 \mathrm{mg} / 1$ \\
\hline
\end{tabular}

\subsection{Bioremediation and Natural Attenuation}

The experiment was designed using Response Surface Methodology, and after performing 17 experimental runs of the Box-Behnken design (BBD) and one control (see Table 2 ), the results of the statistical experiments were analyzed with reverence to the coded design matrix. The regression equation showed that Diesel degradation rate was an experimental function of test variables in coded units. The result from Table 4 showed that on day 28 ( $4^{\text {th }}$ week $)$, diesel content had decreased in all the soil microcosms.

In control, natural Bioattenuation removed 21.15\% of petroleum hydrocarbons from the soil. It was observed that the respective reduction in petroleum hydrocarbon (TPH) of soil microcosms with amendments was much higher when compared to control in the same period in Table 4. This observation showed that the addition of biostimulants increased the rate of TPH degradation in the soil. This is in agreement with the report of [3] that an increase SEO biodegradation with the addition of biostimulants such as NPK, Tween 80 and Pig Manure as supplements. However, [9]; stated that one of the major factors limiting degradation of hydrocarbons is their low availability to the microbial cells [9]. In addition, hydrocarbon-oxidizing potential has also been shown to increase with hydrocarbon exposure. Thus, in Table 4, run numbers 12 and 13 (at lower concentration of Poultry droppings and $\mathrm{H}_{2} \mathrm{O}_{2}$ ), and run numbers 8 and 9 (at higher concentration of Poultry droppings and $\mathrm{H}_{2} \mathrm{O}_{2}$ ) had same remediation conditions but with different surfactant (Tween 80) concentration, results showed that addition of surfactant can enhance diesel degradation. Similar observations was made by [6] concerning the impact of biosurfactants on soil bioremediation.

The effect of different concentrations of hydrogen peroxide supplementation were investigated at the same condition of Poultry droppings and Tween 80 (run numbers 4 and 8 , and run numbers 5 and 14) and the findings demonstrated that addition of hydrogen peroxide $\left(\mathrm{H}_{2} \mathrm{O}_{2}\right)$ can enhance the bioremediation process of soil contaminated with diesel. This is in agreement with [4]. On the other hand; run numbers 11 and 12 and run numbers 5 and 7 through similar condition but with different amount of Poultry droppings were tested and the results showed that extra amount of Poultry droppings can improve diesel removal from contaminated soil.

Table 4. Experimental design and Results for bioremediation of Diesel polluted soil.

\begin{tabular}{lll}
\hline Run & Percentage of Diesel removal \\
\hline & Observed value & Predicted value \\
\hline 1 & 56.260 & 56.446 \\
2 & 41.670 & 41.554 \\
3 & 56.780 & 56.446 \\
4 & 42.470 & 42.685 \\
5 & 47.760 & 47.709 \\
6 & 56.240 & 56.446 \\
7 & 46.580 & 46.249 \\
8 & 44.930 & 44.763 \\
9 & 45.700 & 45.485 \\
10 & 48.210 & 48.261 \\
11 & 41.570 & 41.406 \\
12 & 39.190 & 39.306 \\
13 & 40.660 & 40.824 \\
14 & 49.300 & 49.631 \\
15 & 43.460 & 43.627 \\
16 & 56.320 & 56.446 \\
17 & 56.630 & 56.446 \\
18 (control) & 21.15 & - \\
\hline
\end{tabular}

\subsection{Second Order Polynomial Regression Model and Statistical Analysis}

The experimental data were fitted to a second order polynomial regression model containing 3 linear, 3 quadratic and 3 interaction terms [10] using the same experimental design software to derive the Regression equation for diesel 
removal from polluted soil as stated in eqn. 3 :

$$
\begin{aligned}
& Y=\beta 0+\beta 1 A+\beta 2 B+\beta 3 C+\beta 11 A 2+\beta 2^{2} B 2+\beta \\
& 33 C 2+\beta 12 A B+\beta 13 A C+\beta 23 B C
\end{aligned}
$$

where $\beta 0$ is the value of the fixed response at the center point of the design; $\beta 1, \beta 2, \beta 3$ are linear coefficients; $\beta 12, \beta 13, \beta 23$ are quadratic coefficients; are the interaction effect coefficients regression terms, respectively; A, B and C are the levels of independent variables. The significance of each coefficient in the equation was determined by F-test and Pvalues. F-test showed that all the factors and interactions considered in the experimental design are statistically significant i.e. $\mathrm{P}<0.05$, at $95 \%$ confidence level. The regression equation obtained after analysis of variance gave the level of diesel removal as a function of the different biostimulation variables: Tween 80 , Poultry droppings, and Hydrogen peroxide.

The response $(\mathrm{Y})$ generated is:

$$
\begin{aligned}
Y= & 56.45+0.42 A+0.71 B+0.98 C-9.75 A 2-5.93 B^{2}- \\
& 2.56 C^{2}-0.34 A B-0.055 A C-0.023 B C
\end{aligned}
$$

Where A is Tween 80 concentration, B is Poultry Droppings concentration; $\mathrm{C}$ is Hydrogen peroxide concentrations. To test the fit of the model, the regression equation and determination coefficient $\left(R^{2}\right)$ were evaluated. The model F-value of 717.44 infers the model is significant. The low probability value $(<0.0001)$ indicates that the model is significant. Coefficient determination $\left(\mathrm{R}^{2}=\right.$ 0.9989) being a measure of goodness of fit to the model indicated a high degree of correlation between the observed value and predicted values. The determination coefficient $\left(\mathrm{R}^{2}=0.9989\right)$, suggested that more than $99.89 \%$ of the variance is attributable to the variables and indicated a high significance of the model. Thus, $0.11 \%$ of the total variance cannot be explained by the model. The fitted model was considered adequate if the F-test is significant $(\mathrm{P}<0.05)$ [4]. The Analysis Of Variance (ANOVA) as shown in Table 5 demonstrated that the model was highly significant, as was apparent from the very low probability $(\mathrm{P}<0.0001)$ of the $\mathrm{F}$ - test and insignificant result from the Lack of Fit model $(\mathrm{P}=0.1948)$. The lack of fit test was implemented by comparing the variability of the current model residuals to the variability between observations at replicate settings of the factors. The Lack of Fit F-value of 2.54 implied the Lack of Fit is not significant relative to the pure error.

The Lack of Fit was designed to determine whether the selected model is adequate to describe the observed data, or whether a more complicated model should be used. The Predicted R-Squared value of 0.9881 is in reasonable agreement with the Adjusted R Squared value of 0.9975 . Adequate Precision measures the signal to noise ratio. A ratio $>4$ is desirable. The ratio of 71.064 obtained in this research indicates an adequate signal. This model can be used to navigate the design space.

The coefficient of variation $(\mathrm{CV})$ as the ratio of the standard error of estimate to the mean value of the observed response is a measure of reproducibility of the model, generally a model can be considered reasonably reproducible if its $\mathrm{CV}$ is not greater than 10 per cent. Hence, the low variation Coefficient value $(\mathrm{CV}=0.66$ per cent) obtained indicates a high precision and reliability of the experiments. The coefficient of the model (parameter estimation) and the corresponding P-values are presented in Table 6.

The significant regression coefficients was considered, ignoring those with an insignificant effect on the response at a significance level of $95 \%$. The P-values of the regression coefficients suggested that among the test variables, linear, quadratic and interaction effects of Tween 80, Poultry Droppings and hydrogen peroxide are highly significant. The insignificant effects (factors and interactions) with $\mathrm{P}$-values higher than 0.05 , were ignored. In this study, $\mathrm{A}, \mathrm{B}, \mathrm{C}, \mathrm{A}^{2}, \mathrm{~B}^{2}, \mathrm{C}^{2}, \mathrm{AB}, \mathrm{AC}$ and $\mathrm{BC}$ are significant model terms. Thus, statistical analysis of all the experimental data showed that NPK fertilizer, Tween 80 and hydrogen peroxide concentration had a substantial effect on diesel removal in this study.

Table 5. Analysis of variance (ANOVA) for the quadratic response surface model fitting to the biodegradation data of diesel.

\begin{tabular}{llllll}
\hline Source & $\begin{array}{l}\text { Sum of } \\
\text { Squares }\end{array}$ & DF & $\begin{array}{l}\text { Mean } \\
\text { Square }\end{array}$ & F-value & $\begin{array}{l}\text { P- } \\
\text { value }\end{array}$ \\
\hline Model & 638.54 & 9 & 70.95 & 717.44 & $<0.0001$ \\
Residual & 0.69 & 7 & 0.099 & - & - \\
Lack of Fit & 0.45 & 3 & 0.15 & 2.54 & 0.1948 \\
$\begin{array}{l}\text { Pure Error } \\
\text { Correlation }\end{array}$ & 0.24 & 4 & 0.060 & - & - \\
Total & 639.23 & 16 & - & - & - \\
\hline
\end{tabular}

Standard deviation $=0.31$ C. $\mathrm{V}=0.66 \mathrm{R}^{2}=0.9989$.

Adjusted $\mathrm{R}^{2}=0.9975$, Predicted $\mathrm{R}^{2}=0.9881$, Adequate Precision $=71.064$.

Table 6. Coefficient of the model for diesel biodegradation.

\begin{tabular}{llllll}
\hline Variables & $\begin{array}{l}\text { Coefficient } \\
\text { Estimate }\end{array}$ & $\begin{array}{l}\text { Standard } \\
\text { Error }\end{array}$ & F-value & P-value & Remarks \\
\hline$\beta 0$ & 56.45 & 0.14 & 717.44 & $<0.0001$ & Significant \\
$\beta 1$ & 0.42 & 0.11 & 14.02 & 0.0072 & Significant \\
$\beta 2$ & 0.71 & 0.11 & 40.49 & 0.0004 & Significant \\
$\beta 3$ & 0.98 & 0.11 & 78.29 & $<0.0001$ & Significant \\
$\beta 11$ & -9.75 & 0.15 & 4045.81 & $<0.0001$ & Significant \\
$\beta 22$ & -5.93 & 0.15 & 1494.94 & $<0.0001$ & Significant \\
$\beta 33$ & -2.56 & 0.15 & 278.60 & $<0.0001$ & Significant \\
$\beta 12$ & -0.34 & 0.16 & 4.74 & 0.0658 & Significant \\
$\beta 13$ & -0.055 & 0.16 & 0.12 & 0.7368 & Significant \\
$\beta 23$ & -0.023 & 0.16 & 0.020 & 0.8902 & Significant \\
\hline
\end{tabular}

Figure 1 showed the studentized residuals and normal per cent probability plot. Residual showed the difference between the observed value of a response measurement and the value that is fitted under the theorized model. Small residual values indicated that model prediction is accurate. 
The predicted versus actual plot of diesel oil biodegradation were shown in Figure 2. Actual values were determined for a particular run and the predicted values were calculated from the approximating function used for the model. The Cooks distance and studentized residuals illustrated the normal distribution and constant variance of the residuals, the goodness of fit, linearity of the fitted model, and the independence. Figure 2c showed Cook's distance plot; according to this plot there were no points that were potentially powerful due to their location in the factor.

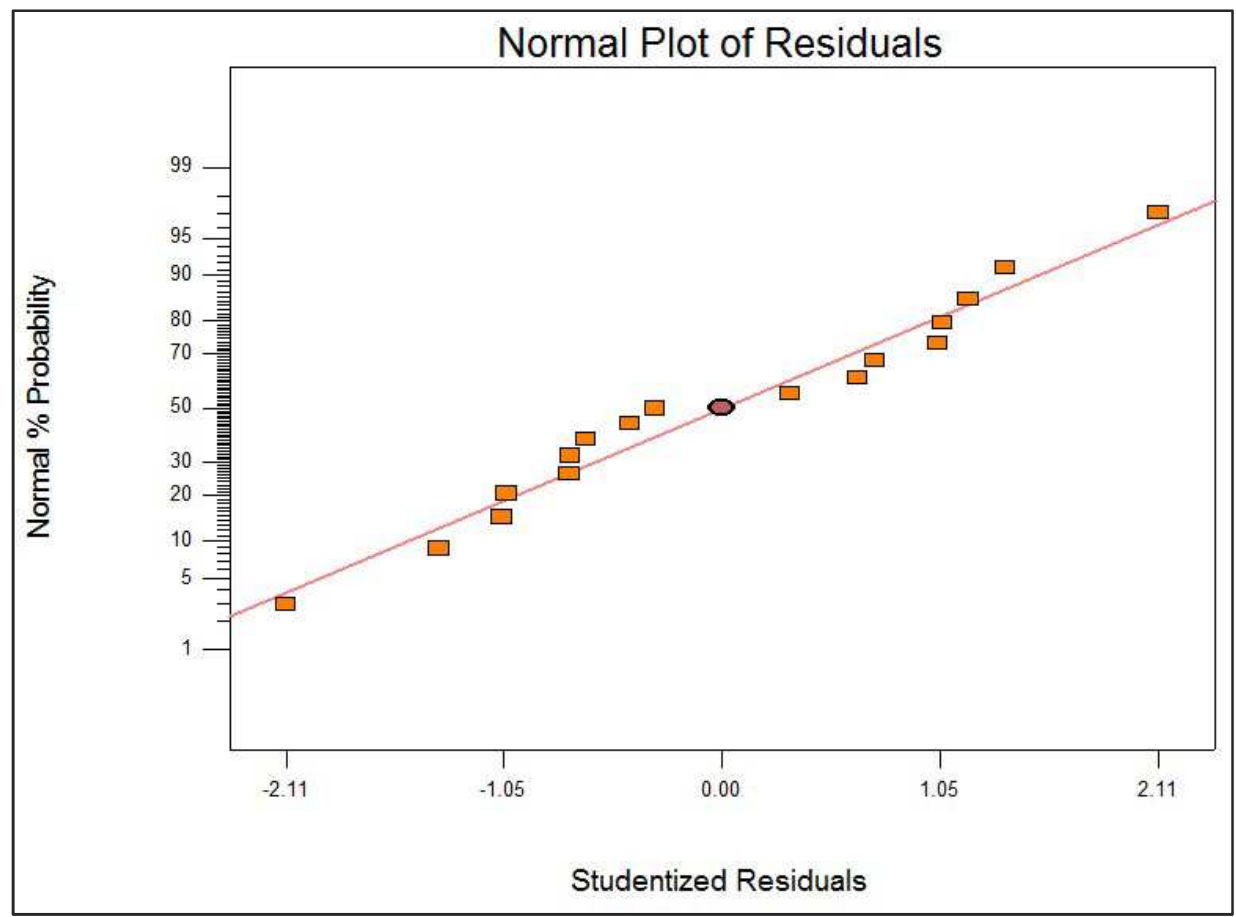

Figure 1. Normal plot of residuals plot of soil diesel bioremediation.

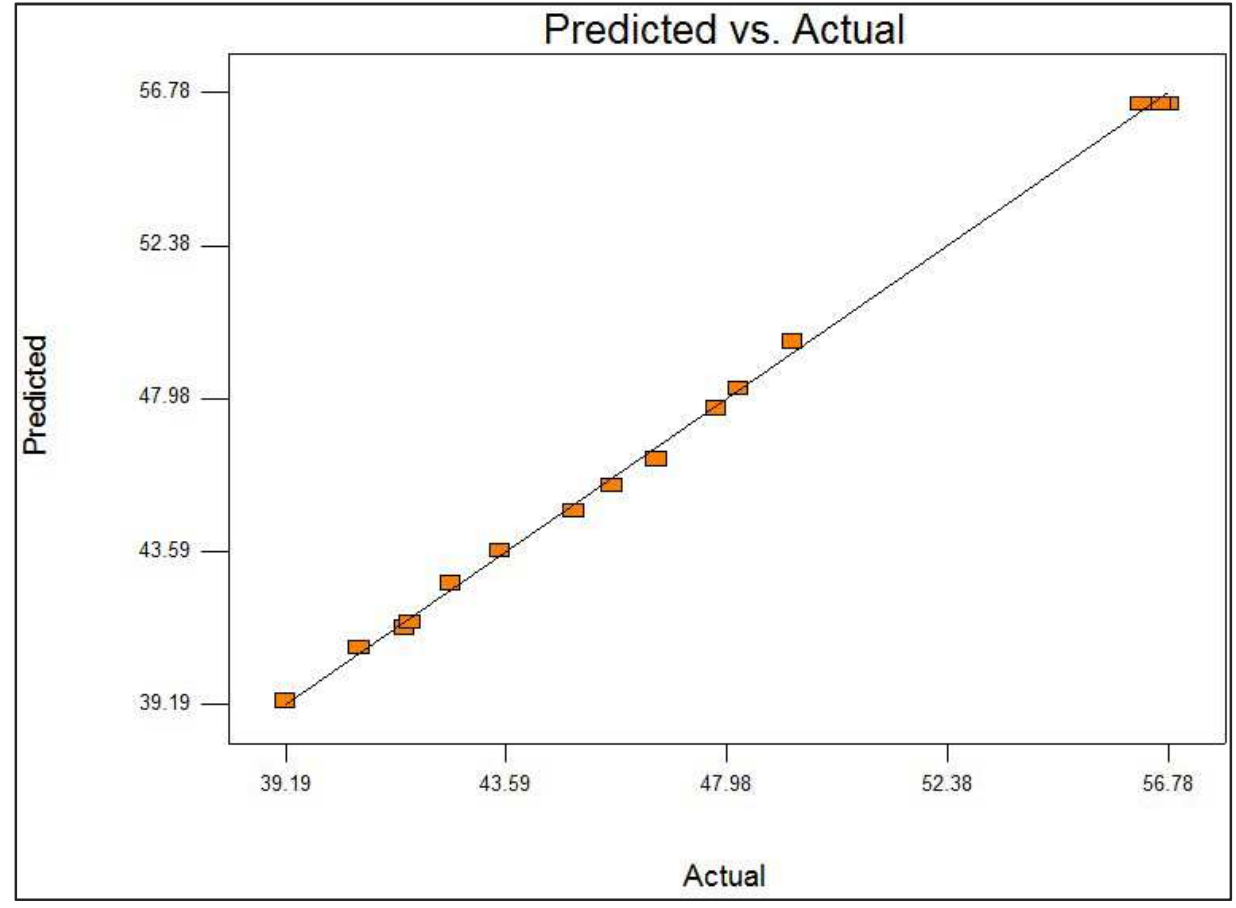

Figure 2. Predicted versus actual plot of soil diesel bioremediation. 


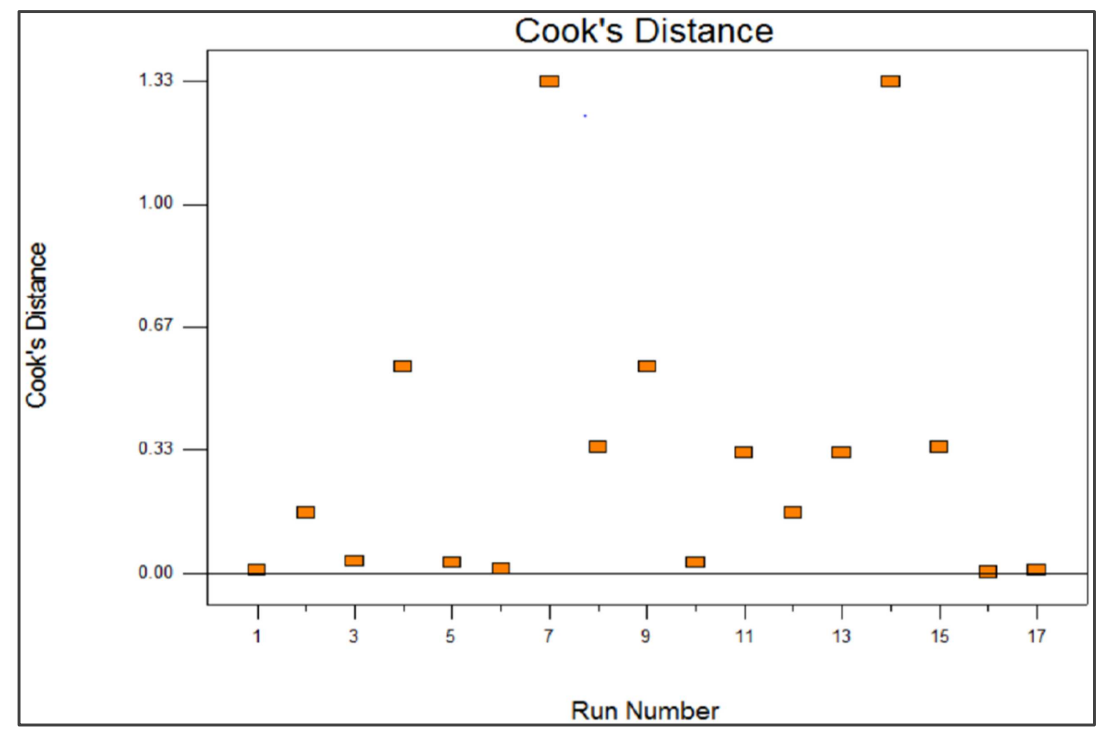

Figure 3. Cook's distance plot of soil diesel bioremediation.

\subsection{Interaction Among Factors That Influence Diesel Oil Removal}

The graphical representation of the response shown in Figures 4- 6 showed the effect of Tween 80 (A), Poultry droppings (B) and hydrogen peroxide (C) on removal of diesel. The effect of the interaction of poultry droppings and Tween 80 on diesel bioremediation is illustrated in Figure 4. It was observed in this study that; higher rate of diesel removal was attained with higher surfactant (Tween 80) concentration and relatively high amount of Poultry droppings. The maximum degradation yield of diesel $(56.5652 \%)$ was obtained with $10.10 \mathrm{ml}$ of Tween 80 surfactant and $41.47 \mathrm{~g}$ of Poultry droppings at a fixed hydrogen peroxide concentration of $1.10 \mathrm{ml}$. This was because of better bioavailability of substrate for the inherent microorganisms.

Figure 5 shows the $3 \mathrm{D}$ response surface plot of the interaction effect between Tween 80 and hydrogen peroxide $\left(\mathrm{H}_{2} \mathrm{O}_{2}\right)$ concentrations. This plot demonstrated that both Tween 80 and hydrogen peroxide have the best interaction performance at optimum concentrations. A higher percent diesel oil removal was obtained at a higher hydrogen peroxide concentration with relatively high amount of tween 80. This three dimensional plot explained that both tween 80 and hydrogen peroxide have individual impact on diesel oil removal as the individual coefficient of both Tween 80 and hydrogen peroxide is positive and their interaction effect is positive. Figure 4.6 showed the response surface 3D plot of the effect of interaction between Poultry droppings and hydrogen peroxide concentrations. Higher rate of diesel oil removal was observed with increase in hydrogen peroxide and poultry droppings concentration due to positive interaction effect. Due to dominating interaction effects of hydrogen peroxide, higher levels of this variable gave higher yields of diesel oil removal.

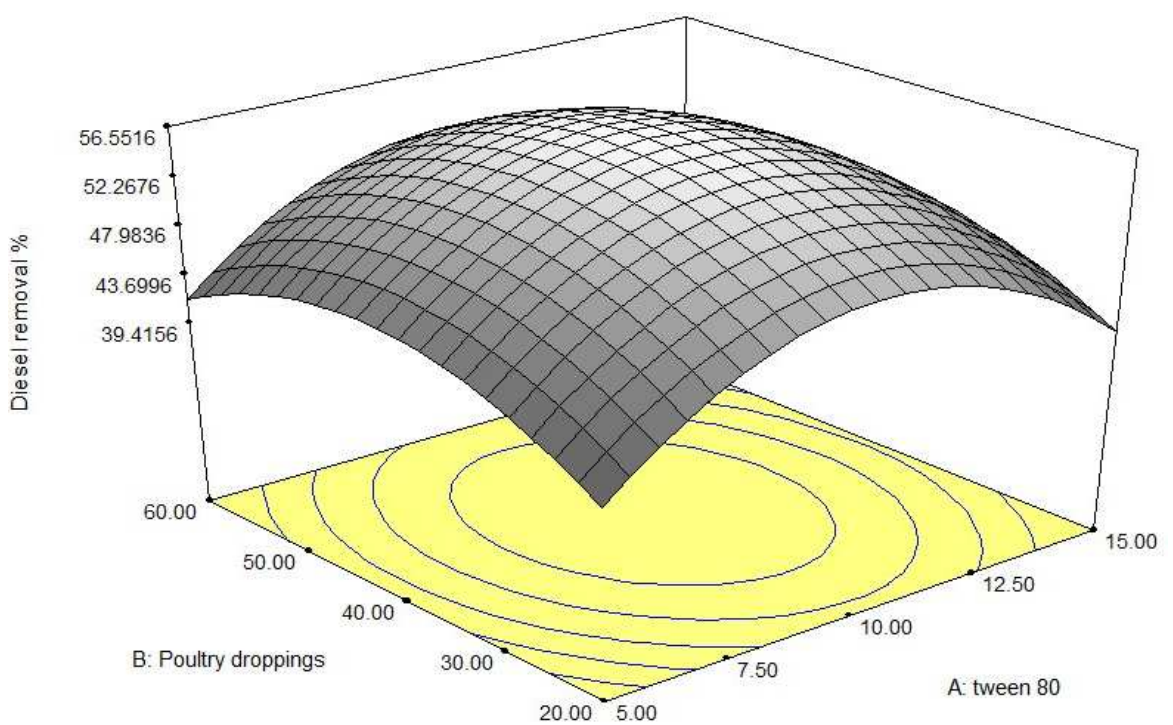

Figure 4. Response surface 3D plots indicating interaction effects of factors Tween 80 and Poultry droppings. 


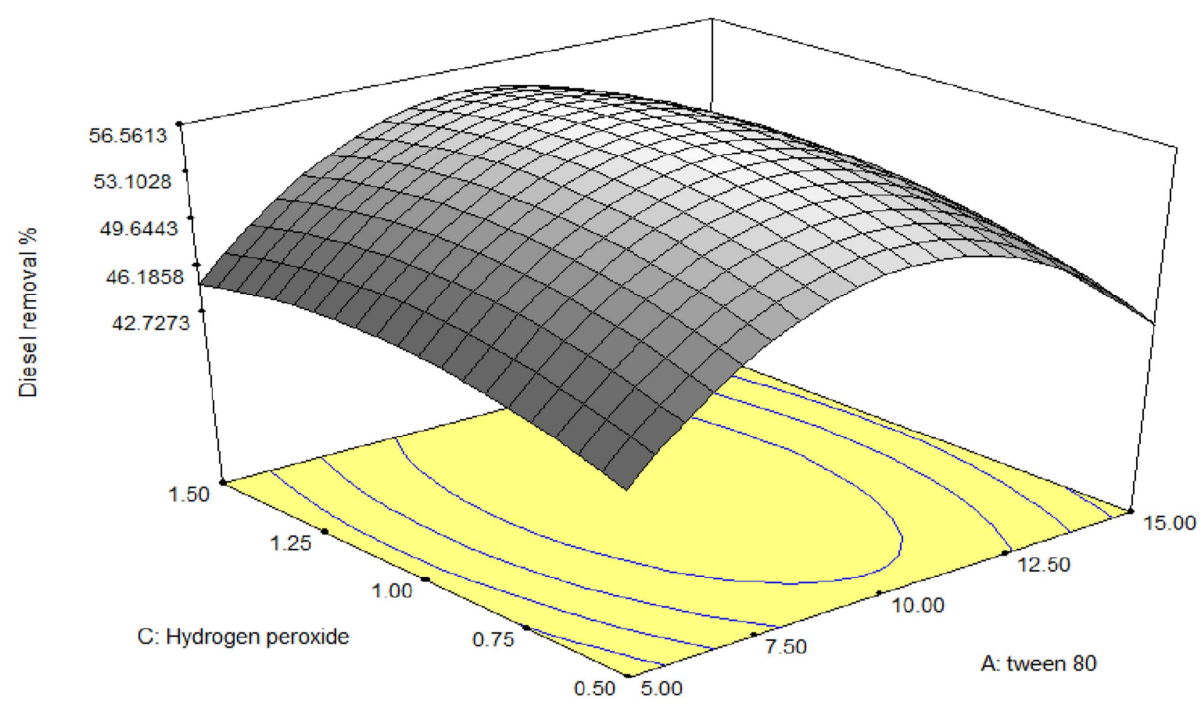

Figure 5. Response surface 3D plots indicating interaction effects of factors Tween 80 and hydrogen peroxide.

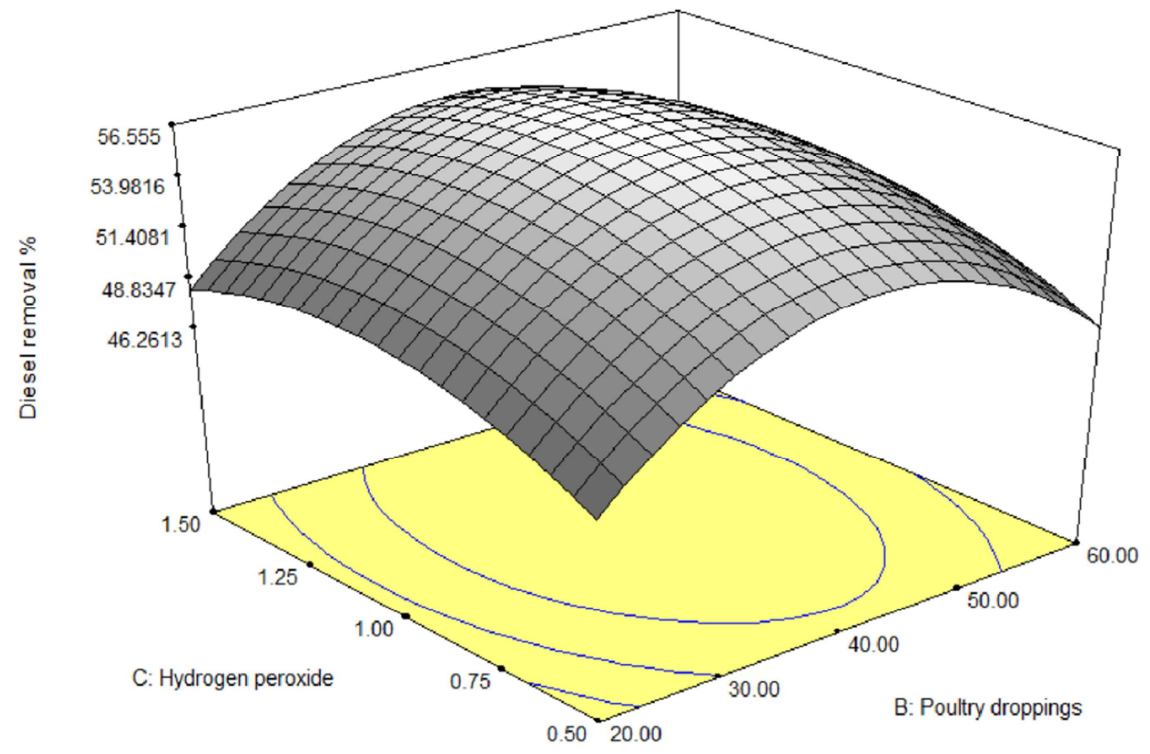

Figure 6. Response surface 3D plots indicating interaction effects of Poultry droppings and hydrogen Peroxide.

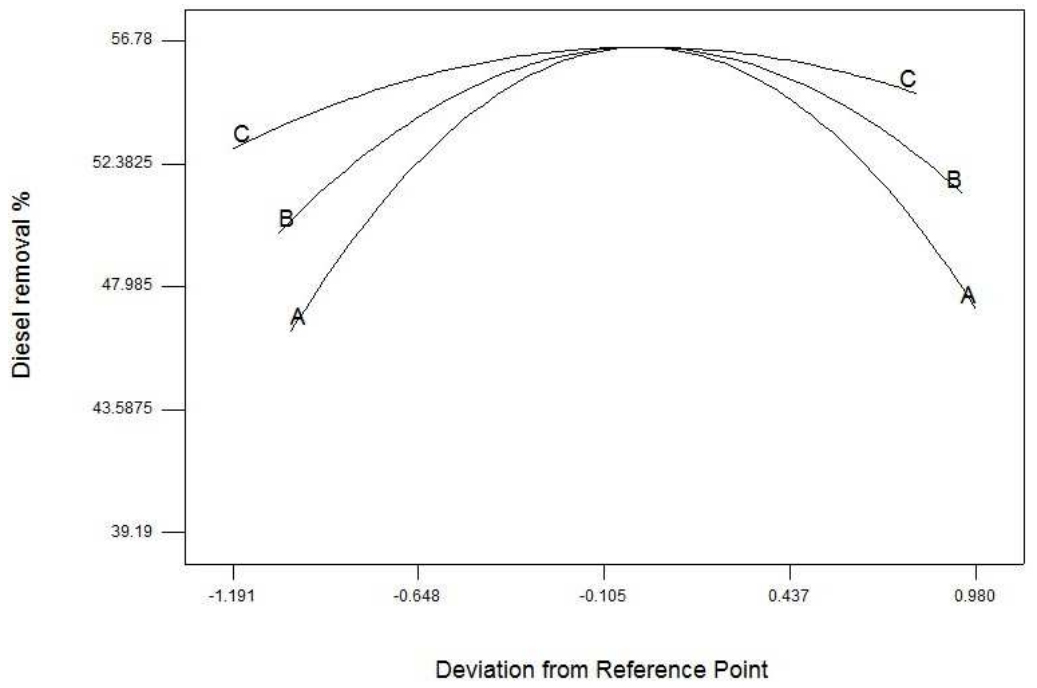

Figure 7. Factor plot representing the individual variable effect on diesel bioremediation ( $A=$ Tween $80, B=$ Poultry droppings and $C=H y d r o g e n$ peroxide). 


\subsection{Factor Plot}

The factor effect function plot was used to assess the effect of each factor graphically. From the trace plot as shown in Figure 7, it showed that each of the three variables used in the present study has its distinct effect on diesel removal by the inherent microbial populations in the soil. Gradual increase in Tween 80, Poultry droppings and hydrogen peroxide concentrations from low level (coded value -1 ) to a higher level (coded value +1 ) resulted in both increase and decrease of diesel oil degradation. Moreover, it was also observed from Figure 7 that over the range of -1 to +1 of Tween 80 , the diesel degradation change in a wide range, which was also the case for Poultry droppings. However, for hydrogen peroxide the diesel oil removal did not change much over a wide range. This clearly indicates that keeping hydrogen peroxide at the optimum level, a change in Poultry droppings and Tween 80 concentrations will respectively affect the process more severely than done otherwise.

\subsection{Optimization and Validation}

Numerical optimization technique based on desirability function was used to determine the workable optimum conditions for the diesel oil bioremediation process. In order to provide an ideal case for biodegradation, the goal for Tween 80, Poultry droppings and hydrogen peroxide was set in range based upon the requirements of the diesel bioremediation and diesel oil removal was set on maximize. The predicted optimum (uncoded) values of Tween 80, Poultry droppings and hydrogen peroxide were found to be: $10.10 \mathrm{ml}, 41.46 \mathrm{~g}$ and $1.10 \mathrm{ml}$, respectively, to achieve $56.565 \%$ maximum diesel oil removal; while desirability for the predicted optimum values was 0.988 (Figure 8).

Nevertheless, validation experiment was conducted to determine the optimum diesel oil removal when the biostimulation factors were set at the favorable optimum levels established above, through BBD and RSM. Standard deviation and percent error were investigated for validation of experiments. Errors between predicted and actual values were calculated according to the formula below:

$$
\text { Error }=\frac{\text { Actual }- \text { PredictedError }}{\text { ActualError }} X 100
$$

At the optimized condition for diesel removal, 56.586\% diesel removal was obtained. The percentage error between the predicted and actual values was found to be $0.037 \%$. The results clearly showed that no substantial difference was observed.

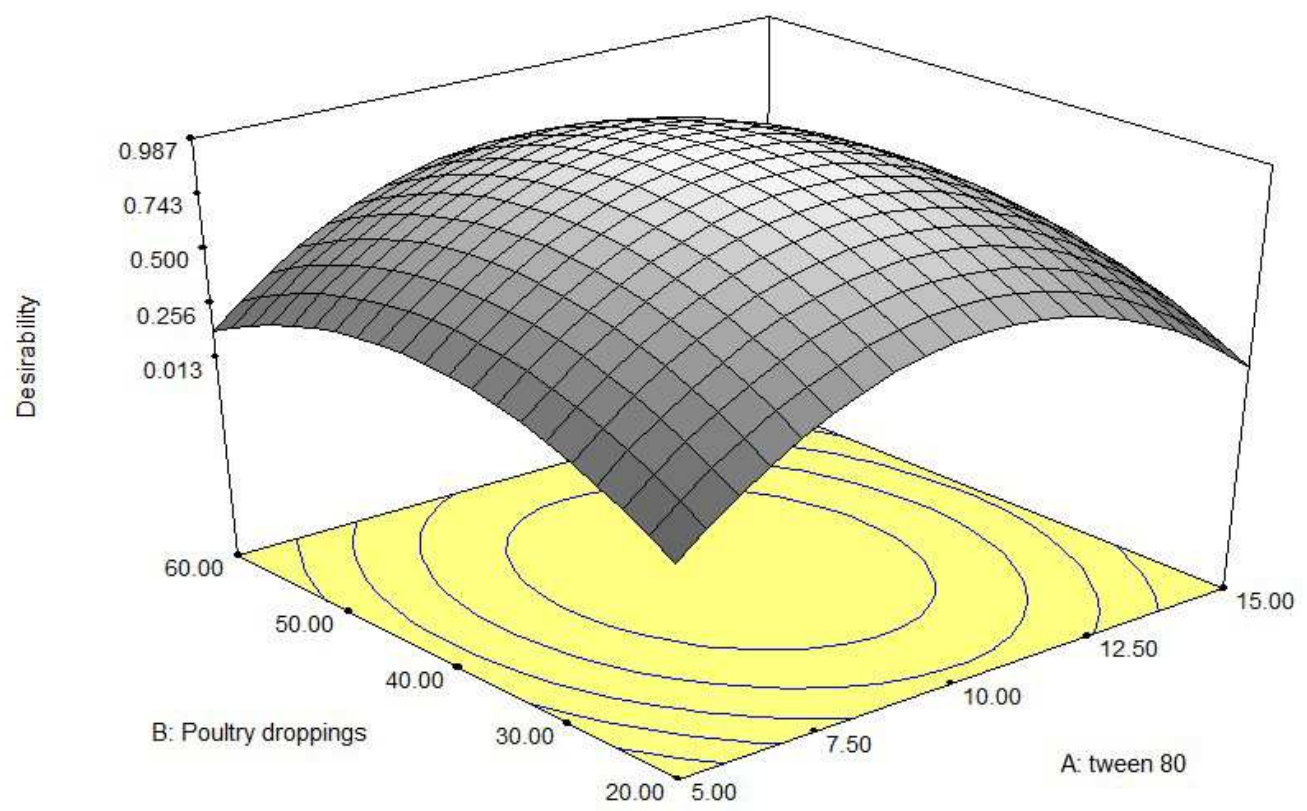

Figure 8. Desirability plot to optimize the bioremediation of diesel-polluted soil process.

\section{Conclusion}

This study investigated the bioremediation of diesel polluted soil and its optimization using Response Surface Methodology. The diesel contaminated soil was incubated for 28 days bioremediation period and statistical analysis was carried out. The predicted optimum parameters were Tween 80: $10.10 \mathrm{ml}$, Poultry droppings: $41.46 \mathrm{~g}$ and hydrogen peroxide: $1.10 \mathrm{ml}$. The optimal diesel oil removal was gotten to be $56.565 \%$. At this optimum condition, the observed diesel oil removal was found to be $56.586 \%$. It can be concluded that bioremediation resulted in petroleum hydrocarbon degradation.

\section{Acknowledgement}

The authors thank the Chancellor and also all the staff of Chemical Engineering Department of Landmark University, Omu-Aran, kwara State; Nigeria. 


\section{References}

[1] Ameh A. O, Mohammed Dabo I. A, Ibrahim S., Ameh J. B, (2013). Earthworm-assisted bioremediation of Petroleum Hydrocarbon contaminated soil from Mechanic Workshop". Afr. J. Environ. Sci. and Technol: 7(6): 531-539.

[2] Ameh A. O, Mohammed Dabo I. A, Ibrahim S., Ameh J. B, T. K Bello, (2012). "The effect of Surface Area and Periodic Tilling on the Bioremediation of Used Engine Oil contaminated soil". Niger. J. Sci: 46: 9-11.nter. J. Ener. \& Envrion, Eng: 1-14.

[3] Agarry, S. E. and Ogunleye, O. O (2012) Box-Behnken Design Application to study enhanced bioremediation of soil artificially contaminated with spent engine oil suing biostimulation strategy.

[4] Agarry, S. E, Owabor, C. N, Yusuf, RO, (2012): Enhanced bioremediation of soil artificially contaminated with kerosene: optimization of biostimulation agents through statistical experimental design. J. Pet. Environ. Biotechnol: 3: 120.

[5] Chaineau, C., Setier, J. and Morillon, A. (2002), Is bioremediation a solution for the treatment of oily waste? Society of Petroleum Engineers Inc. SPE78548: 1-10.

[6] Franzetti, A; Gandolfi, I; Bestetti, G; Smyth, T.PJ and Banat, M. (2010) Production and applications of trehalose lipid biosurfantant. Eur. J. Lipids Sci. and Technol: 112: 617-627.
[7] Gee, G. W and Bauder, J. W (1986) Particle Size Analysis by hudrometer. Asimplified method for routine analysis and a sensitivity test of measurement parameters. Soil. Sci. Soc. Am. J.: 43: 1004-1007.

[8] Hamdi H, Benzarti S., Manusadzianas L, Aoyama I and Jedidi N 2007: Bioaugmentation and Biostimulation effects on PAH dissipation and soil ecotoxicity under controlled conditions. Soil Biol Biochem; 39: 1926-35.

[9] Mohajeri, L; AbduAziz, H; Isa, M. H; and Zaheed, M. A (2010) A statistical experimental design application for optimizing biodegration of weathered crude oil in coastal sediaments. Bioresour. Technol: 101: 893-900.

[10] Montgomery DC (2008) Design and Analysis of Experiments. (Seventh Ed.) John Wiley, New York.

[11] Mozik, A. and Seget, Z. F (2010). "Bioaugmentation as a strategy for cleaning up of Soils contaminated with Aromatic Compounds". Microbial. Res. 165: 363-375.

[12] Srivastava, S and Thakur, I. S (2006) Bio sorption potency of Aspergillusniger for removal of chromium (VI). Curren. Microbio: 153: 232-237.

[13] Vidali, M. (2001), Bioremediation: An overview. J. Appl. Chem. 73 (7): 1163-1172. 